\title{
Cálculos financieros y fronteras sociales en una economía de deuda y morralla*
}

\author{
Financial calculations and social boundaries \\ in a debt and cash economy
}

Magdalena Villarreal**

\begin{abstract}
Resumen: Se exploran los marcos de cálculo y valoración en las prácticas financieras cotidianas de mujeres en barrios marginados de la ciudad de Guadalajara a partir de un estudio etnográfico y cuantitativo realizado en 2007. Se argumenta que la lucha por incrementar y hacer rendir ingresos, recursos y capitales involucra múltiples dimensiones de la vida cotidiana y se conjuga en términos sociales y culturales. Aunque no se definan estrictamente como capitalistas, muchas de estas relaciones pueden actuar para mediar y estructurar procesos monetarios.
\end{abstract}

Palabras clave: Cálculos financieros; Fronteras sociales; Calculabilidad; Pobreza

\begin{abstract}
The article explores frameworks of calculation and value attribution in women's everyday financial practices in the context of a cash and debt economy. The analysis is based on ethnographic information, as well as a survey carried out in 2007 within marginal sectors of the city of Guadalajara. It is argued that the struggle to increase and make the most of income, resources and capitals engages social and cultural aspects and involves multiple dimensions of everyday life. Many of the relations entailed - which might not be strictly defined as capitalist - may act to mediate and structure monetary processes.
\end{abstract}

Keywords: Financial calculations; Social boundaries; Calculability; Poverty

* Morralla: dinero menudo o moneda de bajo valor.

**Profesora e investigadora titular "C" del CIESAS Occidente (Guadalajara, México) y nivel II del Sistema Nacional de Investigadores. En 1994 obtuvo doctorado Cum Laude en la Universidad de Wageningen en Holanda. Sus publicaciones más recientes incluyen: Mujeres, finanzas sociales y violencia económica en zonas marginadas de Guadalajara; Antropología de la deuda: crédito, ahorro, fiado y prestado en las finanzas cotidianas.<magdalena.villarreal@ gmail.com>.

\begin{tabular}{|l|l|l|l|l|l|}
\hline Civitas & Porto Alegre & v. 10 & n. 3 & p. 392-409 & set.-dez. 2010 \\
\hline
\end{tabular}


"Ir al día" describe la manera en que gran cantidad de personas enfrentan sus gastos. Cotidianamente surgen imprevistos que es necesario cubrir de una manera u otra, y el margen de planeación es escaso. En los cálculos pesa sobremanera la consideración de que es muy posible que no haya recursos monetarios en un futuro inmediato y, quizás tampoco a mediano plazo.

Estos cálculos son el foco de discusión en las líneas que siguen. El argumento central es que la lucha por incrementar y hacer rendir ingresos, recursos y capitales involucra múltiples dimensiones de la vida cotidiana y se conjuga en términos sociales y culturales. En la economía de sectores de bajos recursos - al igual que en los sectores más "adinerados" -, las sumas y restas se significan a la luz de creencias, temores y esperanzas. Hay ruidos, filtros y distorsiones. Las normas morales que entran en juego para ciertos cálculos se pueden ver transfiguradas en contextos guiados por la obtención de estatus o ganancia monetaria. Pero el llegar a una mejor comprensión de tales conjugaciones puede requerir el destrabar algunas fórmulas estereotipadas que tienden a oscurecer elementos cruciales en la configuración de la economía. Estas tienen que ver, entre otras cuestiones, con la valoración diferencial que se hace de los recursos y el dinero.

Nos referimos aquí de los distintos marcos de cálculo y procesos de calculabilidad que entran en juego en las transacciones y toma de decisiones. Recurrimos a la noción de calculabilidad introducida por Callon (1998), puesto que no se trata necesariamente de mecanismos racionales de cálculo, sino de los marcos en los que ciertos esquemas de procesamiento de información se habilitan o deshabilitan, de los márgenes para realizar interpretaciones y las herramientas con las que se cuenta para ello. Dichos marcos se generan y reproducen en las relaciones sociales. La escasez de circulante hace aún más visibles los mecanismos no monetarios que entran en juego en una economía, y el análisis de estos brinda elementos críticos para la comprensión de los factores que contribuyen a la reproducción de la pobreza.

$\mathrm{Y}$ es que la economía funciona a través del establecimiento de equivalencias entre bienes, servicios y sus representaciones pecunarias. Estas no son fijas: la paridad se determina en función de una serie de consideraciones, entre las que no solo intervienen los precios fijados por las fuerzas del mercado global, nacional o regional, sino también cuestiones muy locales vinculadas a temporalidad, oportunidad y riesgos percibidos, en los que las relaciones de poder y los procesos de exclusión juegan un papel fundamental.

La gente recurre a cálculos o "tanteos", con base en la información asequible, en los que se implican consideraciones de valor y conjeturas sobre los posibles costos - tanto sociales como monetarios - además de la 
probabilidad de éxito o fracaso. ${ }^{1}$ No es que se esté en posibilidades de elegir libremente entre una gama de opciones, como pareciera proponerse desde una perspectiva de elección racional (rational choice perspective). Las decisiones están sujetas a la influencia de las relaciones sociales, culturales y emocionales en las que interactúan. Y, al igual que la mayoría de los "actores económicos" del mundo, los pobladores de barrios marginados no necesariamente calculan en función de ganancias y pérdidas monetarias. En ocasiones se responde a una necesidad inmediata, en otras a una emoción (alegría, miedo, inseguridad, por ejemplo), o simplemente se actúa por impulso.

A partir de un estudio ${ }^{2}$ realizado en cuatro bolsones identificados como de extrema pobreza - Lomas del Paraíso, Pueblo Quieto, La Comunidad Mixteca y El Embarcadero ${ }^{3}$ - en la ciudad de Guadalajara, México, pudimos analizar algunos de los elementos críticos que entran en juego en el manejo de finanzas de mujeres, incluidos recursos monetarios y no monetarios. Los sitios corresponden a lo que la Secretaría de Desarrollo Social identifica como polígonos de extrema pobreza. Tres de los estos se establecieron - cuando menos en parte - en terrenos federales y uno, Lomas del Paraíso, en una zona ejidal. En todos los casos se habló, en algún momento de su historia, de los moradores como "paracaidistas" o "invasores". El asentamiento de mayor antigüedad es el de Pueblo Quieto, el cual se fundó en 1962. Lomas del Paraíso y la Comunidad Mixteca se fundaron a finales de la década de los setentas, y Embarcadero en 1997. El nivel de estudios es inferior en los polígonos de más reciente creación, compuestos en gran parte por contingentes de "fuereños" que han migrado a Guadalajara en busca de nuevas oportunidades.

1 El lector podrá observar cómo estos rasgos de la economía se han hecho patentes en la crisis financiera actual.

2 El estudio se realizó entre Julio y Diciembre del 2007. En él participaron Ana Torres, Javier Zamora, Edith Carrillo y Miguel Vizcarra, y fue coordinado por Magdalena Villarreal bajo auspicios del Instituto Municipal de las Mujeres de Guadalajara, El Instituto Jalisciense de las Mujeres y el PAIMEF.

3 En la selección de los sitios se tomó en cuenta que hubiese un contraste en términos de composición social de los pobladores, incluyendo empleo, etnicidad, historia migratoria y tiempo de permanencia en la ciudad. El trabajo etnográfico realizado incluyó estudios de caso a 65 mujeres, en los que se buscó registrar sus historias de vida, sus trayectorias laborales y financieras, y se dio seguimiento tanto a situaciones consideradas como de éxito, como aquellas etiquetadas como fracaso económico. En la segunda etapa se aplicaron 399 cuestionarios a mujeres responsables o corresponsables del hogar, cubriendo el 55\% del total de viviendas de estas cuatro zonas. Esta información se complementó con datos obtenidos del Censo de Población y Vivienda 2000 y Microdatos del Conteo de Población 2005 del Instituto Nacional de Estadística, Geografía e Informática (INEGI). Posteriormente llevamos a cabo 6 grupos focales en los que discutimos algunos de los hallazgos con las pobladoras de los sitios estudiados y retomamos ciertas preguntas que consideramos relevantes a partir de la información obtenida. 
Entre los inmigrantes hay un buen número de mujeres. Algunas - las menos - llegan solas, si acaso acompañadas de un hermano o un cuñado, buscando contactar a algún conocido o familiar. La mayoría viene con sus hijos y/o marido. Encuentran mediano cobijo en barrios escondidos en las entrañas de Guadalajara. Aquí pasan a engrosar las filas de los marginados, discriminados y excluidos de la ciudad. Su caso, sin embargo, no difiere mucho del de otras, que aunque son tapatías 4 , "cayeron" en alguno de estos lugares porque no encontraron otro espacio en la mancha urbana. Y tampoco del de las oriundas, cuyos padres y abuelos establecieron morada en estos barrios desde hace varias décadas. Ahora ellas y sus hijos difícilmente imaginan salir de ellos.

Estos asentamientos albergan a población clasificada en los deciles más bajos en las estadísticas de pobreza de la sociedad tapatía. Cuentan con servicios, pero éstos son parciales y muchas viviendas tienen energía eléctrica mediante "diablitos"s. Son considerados inseguros dada la incidencia de alcoholismo, drogadicción y casos de violencia. Los índices de desempleo son altos y los ingresos inestables. Las mujeres, identificadas como quienes (además de los niños), tienden a sufrir de manera más fuerte las consecuencias de la pobreza y la marginación, juegan un papel fundamental en la consecución de fondos y la búsqueda de alternativas a la pobreza. Manejan finanzas, ahorran, invierten y se endeudan.

Si bien un alto porcentaje de la población no maneja chequera y quizás se confunda si se le pregunta por presupuestos, es claro que "sacan sus cuentas" y calculan sus oportunidades. Entender cómo se realizan estos cálculos es parte de la necesaria comprensión de las finanzas populares, en las que las mujeres juegan un papel fundamental.

Por ello, la mira se enfocó a las mujeres responsables o co-responsables del hogar, indagando sus estrategias para obtener ingresos y cubrir gastos, sus prácticas financieras, los factores que obstaculizan la consecución de sus objetivos y el logro de sus aspiraciones. Pudimos comprobar que la estructura familiar y de redes sociales juega un papel sumamente importante en la configuración de las finanzas. En muchos de estos hogares residen dos, tres y hasta cuatro parejas, la mayor parte de éstas con hijos. Las configuraciones de dependencias y responsabilidades sociales y financieras se extienden más allá de la vivienda, incluyendo vínculos con familiares, amigos, patronos y prestamistas. Se hicieron evidentes múltiples escenarios de discriminación,

\footnotetext{
4 Originarias de Guadalajara.

5 Cables que los habitantes cuelgan ilegalmente de la red eléctrica pública.
} 
marginación y cruda explotación, tanto a nivel de la operación del sistema monetario y de la economía en general, como a nivel de los mecanismos forjados al calor de la oportunidad, la urgencia y la creatividad.

Distintas formas de endeudamiento, préstamo, mano vuelta y crédito adquieren gran relevancia en la consecución y manejo de finanzas, $y$, al igual que en otras economías, aquí se recurre a diversos marcos de cálculo y valoración, generalmente interrelacionados, pero en ocasiones contradictorios.

\section{La economía de deuda y morralla}

En el período comprendido entre julio y noviembre del 2007, cuando se realizó este estudio, Guadalajara resentía los estragos de la fuga de maquiladoras y ya empezaban a aparecer indicios de la inflación que posteriormente se desató con mayor fuerza. El flujo de remesas de Estados Unidos comenzaba a mermar, y el incremento en los costos involucrados en el cruce de la frontera hacia este país llevaba a muchos migrantes del sur de México y de Centroamérica a quedarse en esta ciudad. La dificultad para encontrar una fuente de empleo estable conducía al empobrecimiento de capas medias de la población y a dificultades en la sobrevivencia de los sectores ubicados en la base de la pirámide.

La inestabilidad, además del bajo monto, es la característica más sobresaliente del ingreso monetario en las cuatro zonas estudiadas. No pocas mujeres mencionaron la ansiedad que sentían al no saber si contarían con dinero para la siguiente semana e incluso el siguiente día, explicando que con frecuencia realizaban transacciones poco favorables en términos financieros con tal de obtener algunas monedas para cubrir gastos inmediatos.

De hecho, el 52 por ciento de la población de uno de los cuatro polígonos estudiados contaba con ingresos totales per cápita iguales o menores a 150 pesos semanales ${ }^{6}$ (menos de dos dólares al día). Pero no obstante el exiguo monto de los recursos monetarios disponibles, había un nivel relativamente importante de consumo. Es significativo que el gasto realizado por los moradores dentro de los barrios mismos generaba algún tipo de empleo para la tercera parte de las residentes femeninas ${ }^{7}$ que recibían remuneración por su trabajo. Aquí se incluye, por ejemplo, desde quienes vendían cena en una mesita afuera de su casa por las noches, o ambulaban por las calles ofreciendo elotes $^{8}$, chayotes ${ }^{9}$ cocidos o fruta picada, hasta las dueñas de pequeñas tiendas de abarrotes, regalos, útiles escolares y ropa.

\footnotetext{
El salario mínimo equivalía en ese tiempo a 293 pesos semanales.

Tomando en consideración sólo las jefas o corresponsables del hogar.

Maíz tierno.

9 Fruto parecido a la papa.
} 
Otro punto a resaltar es que, dada la estructura de oportunidades, la educación no constituía necesariamente el elemento crítico en la obtención de mayores ingresos para ellas. La mayor parte de las mujeres que lograban obtener más de cinco salarios mínimos no contaban con estudios o cuando mucho habían terminado la educación primaria, mientras que el 75 por ciento de las pocas que cursaron licenciatura y un alto porcentaje de quienes terminaron la preparatoria se encontraban desempleadas o se dedicaban exclusivamente al hogar.

A pesar de lo magro de sus recursos monetarios, esta población ahorra, invierte, se endeuda y administra dineros. Los servicios financieros institucionales a los que tiene acceso son limitados, altamente fragmentados y desiguales. Pero es común acudir a mueblerías y comercios en los que se obtienen artículos (incluyendo televisores, aparatos de sonido, etc.) en abonos, además de utilizar préstamos prendarios de instituciones tales como el Monte de Piedad. El recurso a instituciones bancarias y sociedades financieras se ha ido incrementando, aunque la gran mayoría aún requiere de prestamistas y familiares o amigos, incluso para cubrir sus compromisos con estas instituciones.

Fue significativo que, tanto en las encuestas como en las entrevistas a profundidad, la mayoría respondió las preguntas sobre ingreso con base en cálculos semanales. Es difícil hacer estimaciones por día, pues hay gran variación entre un día y otro, pero lo importante es "salir la semana". El problema no es menor. Casi la tercera parte de las mujeres afirma no recibir aportación monetaria de su pareja.

$\mathrm{Y}$ es que vendedores ambulantes, lavacoches, jardineros eventuales, cargadores, pintores, músicos y peones de albañil a veces tienen "buenas rachas", pero en ocasiones no ven la suya. Hay un alto grado de desempleo, particularmente en hombres, lo cual, a decir de algunas de las mujeres entrevistadas, explica en parte el alcoholismo y el consumo de drogas de sus parejas e hijos, quienes sufren frustración al sentirse inútiles y rechazados. Esto a su vez les impide encontrar fuentes de empleo, volviéndose un círculo vicioso. La escasez de empleos y la baja remuneración son la constante en las zonas estudiadas. Se afirma que los hombres tienen posibilidad de ganar más que las mujeres, pero sus fuentes de trabajo son más esporádicas. Entre las mujeres que declaran aportar monetariamente al hogar, quienes cuentan con algún tipo de actividad remunerada más o menos estable son en su mayoría empleadas domésticas, obreras, cocineras o dependientas de algún negocio. Muy pocas han accedido al empleo en servicios profesionales.

Existe, en estos polígonos, una amplia gama de arreglos económicos y financieros, parte de los cuales se vinculan a las variaciones de modelos de 
"hogar". Por supuesto, es un error suponer que el hombre es el único proveedor. Más del 40 por ciento de las mujeres responsables o corresponsables del hogar cubren los gastos de sus familias sin aportación monetaria del cónyuge, sea porque no lo tienen o simplemente porque no contribuye. Los hijos contribuyen bajo ciertas circunstancias pero frecuentemente no lo hacen. Y los padres ancianos en ocasiones son proveedores y en ocasiones dependientes. Algunas viudas siguen contribuyendo fuertemente a la economía familiar de sus hijos casados, siempre con la esperanza de que pronto logren salir adelante por sí mismos.

Así, tiende a haber relaciones de dependencia entre padres e hijos aunque no residan en la misma vivienda. Cuando son vecinos, los hijos y sus familias utilizan la electricidad, el baño o un cuartito pegado a las casas de los padres o, aunque no vivan bajo el mismo techo, es común recurrir a ellos cuando requieren un préstamo. Con mucha frecuencia encontramos que son las hijas quienes apelan a los padres para solicitar apoyo financiero, dado que se considera más humillante que el varón demuestre carencia. De igual manera, son las hijas quienes más frecuentemente aportan al hogar. Incluso, las nueras tienden a contribuir más sistemáticamente que los yernos. Pero también son mayoritariamente las hijas y nueras quienes atienden y cuidan a los padres en casos de enfermedad y/o vejez. Aquí podemos ver multidireccionalidad en las relaciones de dependencia en términos de generación, pero no así de género, dado que la responsabilidad de sostener las relaciones con los padres generalmente recae en las hijas o nueras.

Los favores y las "ayudas" forman parte cotidiana de las transacciones económicas, al igual que los préstamos, y, sobre todo, el pago diferido. Este último, conocido como "fiado", es similar a las transacciones realizadas por negocios de distintas envergaduras, incluyendo los grandes monopolios. En la economía de deuda y morralla, sin embargo, las relaciones de poder que significan la transacción son considerablemente distintas.

\section{Marcos de Cálculo y Prácticas Financieras}

Olga, Chepa, Cecilia y Licha ${ }^{10}$, habitantes de los polígonos estudiados, no tienen acceso a los mismos servicios financieros. La falta de "confiabilidad" por su identidad de "pobre" y/o étnica, los problemas legales en la propiedad de sus terrenos, el acercamiento diferenciado a fuentes de información o simplemente el etiquetamiento de su lugar de residencia, se unen a la inestabilidad en sus fuentes de ingreso que impiden o limitan sus opciones.

\footnotetext{
${ }^{10}$ Los nombres son pseudónimos.
} 
Algunas, como Licha - indígena mazateca de 31 años que lleva una década viviendo en un barrio habitado fundamentalmente por mixtecos ${ }^{11}$ - recurren a préstamos de familiares y amistades cercanas, además de los pequeños, pero asiduos ahorros que pueden hacer con base en intenso trabajo y gastos restringidos. Otras, como Chepa - originaria del estado vecino de Nayarit donde ayudaba a su padre a cultivar maíz, frijol y calabaza -, inician pequeños negocios, recurren a crédito por parte de proveedores $\mathrm{y}$, en ocasiones, alguna ayuda institucional. Dan "vueltas" a los recursos monetarios a los que tienen acceso, generando pequeñas ganancias que, sin embargo, se consumen rápidamente, subsanando los "huecos" mediante deudas en la medida de lo posible. Las cuatro mujeres son emprendedoras, pero Cecilia, de Pueblo Quieto - un barrio densamente habitado, perdido en las inmediaciones de una zona de clase media alta ${ }^{12}$, al igual que varias de las mujeres que conocimos, es particularmente creativa en su búsqueda de recursos, ya que ha organizado rifas que funcionan a la vez como forma de ahorro y fuente de crédito, diversificando así sus actividades al instalar un brincolín ${ }^{13}$ para obtener algunos pesos, cuidar niños y ayudar a elaborar comida a sus vecinos, quienes venden lonches a trabajadores.

En Lomas del Paraíso, otro barrio un poco menos deprimido, Olga tuvo acceso a una gama de fuentes de crédito, aunque este manejo de finanzas la llevó a un torbellino de endeudamiento. Ella, en su momento, fue subgerente de una cadena de comida rápida, pudo rescatar el taxi de su marido, sostener una tienda y sacar adelante a sus hijos. Pero las limitaciones con que se topa incluyen el machismo del padre, no contar con estudios medios, el sentimiento de culpabilidad por trabajar y ganar dinero pero no estar con sus hijos, la responsabilidad de cuidar a su madre, falta de información sobre opciones institucionales de apoyo y capacitación y la precariedad con la que funcionan los negocios pequeños en una zona de bajos ingresos. En una etapa de su vida recibió apoyo de amigos y vecinos, pero ahora que acude a sus familiares (sus hijos y su hermano) no encuentra respuesta. Su esperanza se finca en el trabajo de la hija, una joven mujer quien, como Olga misma, no estudia para contribuir a la economía del hogar, lo cual augura la reproducción de un círculo vicioso.

${ }^{11}$ Los mixtecos y los mazatecos son grupos indígenas que habitan en el sureste de la república mexicana.

12 El nombre de Pueblo Quieto lo adquirió porque, cuando en una de sus múltiples incursiones, elementos policíacos entraban en búsqueda de maleantes, los habitantes afirmaban que ellos no eran revoltosos, sino de un pueblo quieto.

13 Tipo de trampolín 
Chepa, del Embarcadero, tampoco encuentra apoyo en redes sociales. Ella, al igual que Olga, supo llevar un negocio medianamente exitoso que luego se viene abajo. Ambas se vieron obligadas a disponer de los recursos de la tienda, "comiéndose el capital" que con sus esfuerzos habían logrado amasar. Hablamos aquí de procesos de empobrecimiento que, en estos sitios, acechan a la vuelta del día. La inseguridad y la vulnerabilidad a la que están sujetas estas mujeres son evidentes.

Esto hace que Cecilia dirija la mirada hacia afuera. Aunque ha sido medianamente exitosa en sus emprendimientos económicos, ve pocas posibilidades de progreso en Pueblo Quieto. Se lamenta de no haber estudiado siquiera la secundaria, pero considera que con esfuerzo se pueden lograr muchas cosas. El problema es el lugar, dice. "En otros lados hay más oportunidades."

Licha, en cambio, concibe su llegada a La Comunidad Mixteca como un logro y un paso adelante y no piensa volver atrás. A diferencia de sus vecinos, se ha alejado de sus redes familiares y comunitarias. Aunque sus actividades económicas se han visto restringidas por su identidad étnica, además de las enfermedades de dos hombres en su vida, su padre y su marido - por la enfermedad de su padre regresa al pueblo y por la de su marido se viene a Guadalajara - la búsqueda de recursos monetarios, para ella, es un medio hacia un fin. Un fin que tiene que ver con el bienestar de la familia.

La mayoría de las mujeres entrevistadas mantienen esta misma actitud frente al trabajo remunerado. Sin embargo, también hay placer en obtener fondos y sentirse realizadas, como en el caso de Olga y Cecilia. Su actividad laboral es, como diría Knight (1923, p. 579-624) "un ámbito de expresión personal y de realización creativa". Los constreñimientos para incorporarse plenamente tienen que ver en parte, con su dedicación a los hijos. Olga se sentía culpable al dejar a sus hijos por ingresar dinero y, a pesar de que su esposo ganaba menos, no consideraron la posibilidad de que éste fuera quien se encargara del hogar. Cecilia, por otro lado, teme dar el paso a Estados Unidos por sus sobrinos y Chepa pone en primer lugar la educación de sus hijos: "que no les falte a ellos, aunque el negocio sufra".

Los problemas de los lugares en que viven también se hacen sentir en cada momento. Todas lamentan la violencia, las pandillas y la drogadicción. El miedo enmarca muchas de sus relaciones, ya que las mujeres que trabajan fuera del hogar mencionan lo peligroso que es para ellas contratarse en turnos nocturnos o tener que salir temprano de la casa por temor a asaltos $\mathrm{y}$ violaciones.

La situación se agudiza con la falta de servicios tales como electricidad y pavimentación. En la búsqueda de remedios, sin embargo, se ven involucrados 
en lo que González de la Rocha (1986, p. 234) denomina, para el caso de Lomas del Paraíso, “autourbanización patronizada políticamente”. El tipo de organización social excluyente que esto genera poco contribuye a la eficiencia y democratización en el uso de los recursos, dado que el acceso se ve mediado por cuestiones de lealtades y conflictos políticos.

En la lucha por la sobrevivencia las redes sociales constituyen un gran apoyo pero éste se combina caprichosamente con apatías, envidias, competencia y franca explotación. Estos elementos entran en juego en los cálculos de las mujeres en torno al manejo de sus vidas, sus recursos y sus finanzas, las cuales se forjan de manera diferenciada de acuerdo a sus posibilidades, experiencias y las expectativas que de ello se derivan.

\section{Fronteras sociales en la administración de carencias}

En algún momento de su trayectoria, la gran mayoría de las mujeres de estos barrios han tenido que recurrir a formas de usura, pagando por ello un precio excesivo. En estos momentos, la disponibilidad de dinero es más importante que su costo.

Las enfermedades, por ejemplo, son las más mencionadas como gastos importantes que generalmente son imprevistos. Ello a pesar de que el 48 por ciento de las mujeres cuenta con alguna prestación de seguridad social. Sin embargo, los costos relacionados con las enfermedades, tales como el tiempo que las mujeres deben dedicar en espera ante las instituciones y al cuidado del enfermo, las dietas especiales y la merma en ingreso por el lapso que no trabajan, invariablemente resultan en gastos no anticipados. Otros imprevistos incluyen accidentes (en particular las inundaciones que recientemente han causado estragos en estas zonas), compromisos familiares y sociales (pago de favores, la necesidad de apoyar a algún familiar o vecino que lo requiere), compra de zapatos y, también el alcoholismo y/o drogadicción de la pareja o alguno de los hijos y la pérdida de empleo.

Esto no implica, sin embargo, que los gastos "previsibles" sean más fáciles de cubrir. Entre los gastos fijos para los que la gente busca prepararse están cuestiones escolares, pago de deudas y los gastos ceremoniales. Pero cuando el ingreso en sí es difícil de predecir, o cuando lo que se percibe en una jornada apenas alcanza a cubrir la sobrevivencia para ese día, los gastos fijos se vuelven necesariamente postergables.

Es de reconocer, además, que los desembolsos en el rubro de alimentación incluyen mercancías que, a ojos externos, pueden considerarse superfluas, tales como refrescos embotellados y comida chatarra. Este tipo de consumo brinda a las mujeres una satisfacción momentánea asequible frente a un mundo 
lleno de negaciones. Pero es importante mencionar que, irónicamente, quienes se dan "el gustito" de comprarse un elote cocido o un menudo los domingos y quienes compran al hiper menudeo en las tiendas de abarrotes del barrio generan empleos localmente. Permiten esa pequeña ganancia (aunque en términos relativos pueda no ser tan pequeña) al tendero, a la señora que busca complementar sus ingresos o al anciano que vende cacahuates en la esquina.

De igual manera, la atribución de identidad -en particular aquélla asociada a distinciones entre "ricos" y "pobres" - lleva a definir de manera diferenciada las nociones de "lujo", "necesidad", "compromiso", "gusto" o "despilfarro". Así, el consumo de aparatos y novedades electrónicas y otros objetos etiquetados como ostentosos en estos sectores puede ser malmirado sobre todo desde quienes se consideran no pobres - bajo la consideración de que los "pobres" no deben gastar sus escasos recursos en lujos, mientras que para una mujer de la localidad puede representar un "gustito" merecido.

Pero un reproche similar puede aplicarse hacia "los ricos" por parte de quienes no consideran serlo. María, una trabajadora doméstica de Pueblo Quieto, narra un pequeño desencuentro con su patrón.

El otro día vi que mi patrón le compró un saco de croquetas al perro. No me lo vas a creer, ¡le costó mil cincuenta pesos! El saco de croquetas le dura una semana. Yo le dije al señor, " $i Q u e ́$ bárbaro! ¿Cómo voy a creer que paga más de mil pesos a la semana?” Yo, fijate, me paga seiscientos a la semana a mí, y nosotros somos tres, y medio que comemos. ¡Pero el perro come re-bien en el platote!, y le digo "¿porqué no se me voltea? ¡Págueme a mí los mil cincuenta y cómprele unas croquetas de seiscientos pesos al perro!" Mira, se quedó agachado y no me dijo nada. Ahora le compra croquetas sueltas al perro y le da un vaso nomás. Pero no me subió el sueldo (María: Pueblo Quieto).

Los gastos percibidos como "más fuertes" frecuentemente se refieren a cuestiones para las que no están preparadas, como son las urgencias médicas. También incluyen aquéllas que se consideran injustificadas pero necesarias. Los egresos implicados en la educación de los hijos, por ejemplo, involucran toda una serie de factores a considerar, desde las posibles dudas con respecto a la redituabilidad de la inversión hasta consideraciones de discriminación social.

En general pudimos observar que los gastos se ejercen de acuerdo a consideraciones económicas, pero también sociales, culturales y éticas. Como aciertan Douglas e Isherwood:

Cada cultura establece los gajos de su realidad moral de diferente manera, y distribuye de acuerdo con los puntos de vista locales aprobaciones y reprobaciones para las virtudes y los vicios... Gastar 
sólo una reducida proporción del ingreso puede ser calificado en un lugar y un tiempo específicos como frugalidad, sabiduría y prudencia; en otros, avaricia, mezquindad y falsía. Por el contrario, una alta proporción de consumo podría ser aprobada como generosa, espléndida y buena en una cultura, mientras que en otra un comportamiento idéntico podría ser calificado como despilfarrador, irresponsable y malo (Douglas e Isherwood, 1990, p. 42).

Así, la realidad moral se establece de diferente manera y se distribuyen aprobaciones y reprobaciones para virtudes y vicios de acuerdo a puntos de vista locales. Los autores explican que "la elección del consumidor a favor de tales o cuales mercancías forma parte de un intento por imponer identidad y sentido al medio ambiente" (Douglas e Isherwood 1990, p. 14). Afirman que el consumo "forma parte de la necesidad social de relacionarse con otras personas y de disponer de objetos de mediación para conseguirlo" (Douglas e Isherwood, 1990, p. 18).

La alimentación se tiende a clasificar en "lo necesario", aunque en las decisiones con respecto a qué alimentos consumir - si se incluye el menudo de los domingos por la mañana y los tacos del viernes por la noche, por ejemplo entren consideraciones de "lo posible". En esta última categoría podría entrar la compra de un estéreo y el pago del mariachi. Y en una sociedad de consumo, como acertadamente lo afirma Bauman (2003, p. 64) “la 'vida normal' es la de los consumidores, siempre preocupados por elegir entre la gran variedad de oportunidades, sensaciones placenteras y ricas experiencias que el mundo les ofrece". Ser pobre, dice, "significa estar excluido de lo que se considera una 'vida normal'; es no estar a la altura de los demás".

Así, los pobladores de estos barrios no sólo están dispuestos a pagar un precio elevado en mueblerías y tiendas departamentales que ofrecen bienes a plazos, sino que también aportan un monto mayor al que pagan otros consumidores por el dinero mismo. La urgencia de contar con recursos monetarios obliga a los prestatarios a aceptar cobros excesivos que van del 120 al 200 por ciento anualizados y a plazos sumamente cortos. Sin embargo, algunas mujeres hablan de los prestamistas con un grado de agradecimiento y respeto, comentando que hacen lo posible por cubrir prontamente la deuda para no "perder su buena voluntad". Ello debido a sus escasas opciones para obtener créditos, el hecho de poder obtener cantidades fuertes rápidamente, y de que ofrecen un grado de privacidad. ${ }^{14}$ Algunos prestamistas recurren a personas de la localidad - generalmente mujeres - para que sean éstas quienes contraten los empréstitos y aseguren su pago a cambio de un porcentaje mínimo.

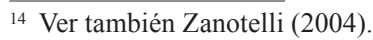


Por otro lado, las prestatarias no siempre pueden cubrir los requisitos para contratar servicios de empresas financieras, y cuando lo hacen, con mucha frecuencia se ven obligadas a recurrir a otros préstamos para saldar sus deudas, utilizando casas de empeño, prestamistas o acudiendo a familiares y amigos. Estos últimos, como hemos mencionado, generalmente se brindan sin intereses, pero el pago de este tipo de favores tiene costos sociales y a veces monetarios, en tanto que habrá que reciprocar de una u otra manera. Este tipo de "circulación" de la deuda brinda pequeños respiros, aunque el costo de las transacciones no disminuye y, en algunos casos, se agrava.

Pedir "fiado" (pago diferido), por ejemplo, es uno de los recursos más socorridos para "salir de apuros" y poder sostenerse. Sin embargo, la gran mayoría de las entrevistadas mencionan la vergüenza y humillación que implica pedir mercancías fiadas. Licha comenta:

Tuve necesidad, pero nunca me atreví a pedir fiado, para nada, si no tenía para comer me aguantaba, pero nunca tuve el valor de pedir, ni un pan fiado, ni nada, me daba mucha vergüenza. Aunque lo necesitara, hacía milagros para que mis hijos no carecieran de lo más necesario, de una tortilla o de un plato de frijoles. No me gusta pedir, porque si pasa algo, si me muero, ¡hasta muerta me van a maldecir! ¡No es bueno andar en boca de la gente! (Licha: Comunidad Mixteca).

Y, como pudimos ver en el caso de Olga, la solidaridad de familiares y amigos no siempre está disponible. En el pasado ella recibió mucho apoyo de parientes y amigos, pero ahora que se siente necesitada de ayuda, no cuenta con ella, o cuando menos, no recibe el grado de auxilio que ella esperaría, en particular de sus hijos y su hermano. Además, se paga un costo social por este apoyo. Silvia, de Pueblo Quieto, comenta:

A mí me da vergüenza, yo no me siento con confianza. Lo que pasa es que aquí hay una cosa, que luego hablan... ¿Para andarles pidiendo? No. Porque luego sale uno a la calle y luego ya se entera uno que dijeron que uno les pidió y a mí no me gusta andar en boca de nadie, por eso mejor me reservo (Silvia: Pueblo Quieto).

Las mujeres juegan un papel fundamental en las decisiones con respecto a la distribución y destino del ingreso en el hogar, pero habrá que tomar en cuenta el complejo entramado de niveles en términos de poder, subordinación e interdependencias en el seno del hogar el cual, por decir lo menos, no es una unidad consensual. ${ }^{15}$

${ }^{15}$ Como bien dice Amartya Sen (1990) — haciendo eco de gran cantidad de estudiosas (os) de las relaciones de género y las familias, y en particular de quienes, como Benería y Roldán (1987), discuten las dinámicas de negociación al interior de la familia. 
Las relaciones sociales que se generan en el seno del "grupo doméstico ampliado" funcionan como factores de estructuración que contribuyen a delimitar la gama de posibilidades de distribución. Aquí entran en juego diferencias en las atribuciones sociales, particularmente con respecto a cuestiones de género. Es preciso mencionar que, en la mayoría de los casos, las mujeres afirman destinar todo el ingreso que ellas obtienen al hogar, en tanto que son contadas quienes conocen siquiera la cantidad precisa que percibe la pareja o los hijos varones. Y no pocas de las entrevistadas manifestaron estar sujetas a las disposiciones de su pareja y sus hijos varones para tomar decisiones en torno a los gastos, particularmente cuando se trata de compras mayores como muebles o electrodomésticos. Sin embargo, una cantidad significativa de mujeres afirman ser ellas quienes toman las decisiones en torno a los gastos, o que lo hacen "de común acuerdo" o en "negociación" con su pareja. Las negociaciones con frecuencia implican esconder información o destinar recursos a otro fin sin que la pareja se entere. De hecho, fue revelador que algunas mujeres no incluyeran los dispendios del marido en ciertos cálculos de gastos familiares, a pesar de nuestra persistente interrogación sobre ello.

No obstante, el control sobre las disposiciones en torno al ingreso es sumamente limitado y parcial. La escasez del recurso monetario es, por supuesto, la primera limitación. Pero además, en las decisiones sobre gastos tienden a priorizar las demandas de los hijos sobre las de ellas mismas, incluso cuando su propia necesidad involucre cuestiones de salud. El marco de calculabilidad se establece aquí en concordancia con prescripciones de género que traspasan su espacio de mando. Aunque hasta cierto punto cuentan con autoridad para manejar "los fondos comunes" - que frecuentemente incluyen la totalidad de su ingreso y sólo parte del de los cohabitantes - y en ocasiones se conceden a sí mismas "algún gustito" (que puede incluir desde una olla de cocina hasta un refresco o unos zapatos), las mujeres aparecen menos como portadoras del control sobre los gastos y la autoridad sobre las decisiones que como responsables de administrar las carencias.

\section{Cálculos financieros y calculabilidad}

La estructura de oportunidades para Cecilia, Olga, Licha, Chepa, Lucía, Soledad, María, Tiburcia y las otras muchas mujeres cuya brega en torno al ingreso analizamos a lo largo del proyecto, poco tiene que ver con el ritmo de trabajo o los logros educativos obtenidos con mucho esfuerzo. Su acceso a fuentes de ingreso - desde el empleo como obrera o trabajadora doméstica hasta la distribuidora de cosméticos por catálogo o la venta de artesanías en 
los cruceros - está íntimamente relacionado a sus trayectorias de vida, su situación geográfica, económica y social, además de la identidad étnica, de clase y de género que se le atribuye. Sus esfuerzos están imbricados en sus responsabilidades como madre, hija, esposa.

Aquí podemos ver “en acción” las maneras en que operan ciertos scripts o guiones de género y clase social. En ellos se definen las fronteras entre lo que será registrado como aceptado, "transgresión" o "patología". Estos contribuyen a la formulación de marcos en los que se organiza la información asequible. El papel de la mujer, por ejemplo, se entreteje con scripts sobre cómo debe comportarse. Como acierta Palomar (2007, p. 96), "se trata de un circuito discursivo poderoso ya que está enraizado en paradigmas morales más o menos consensuados cuya aceptación forma parte ya de lo que pretende: la corrección política, difícil de contradecir o cuestionar sin quedar bajo sospecha de carecer de principios morales". Afirma que:

Los rasgos que define una "buena" y una "mala" madre están subordinados a saberes específicos que, desde los propios esquemas teóricos, argumentan el ideal de la maternidad, sobrecargando a las mujeres de la responsabilidad total de los hijos y produciendo un código moral disfrazado de conocimiento especializado, donde el pecado es no ser "buena" madre y, el castigo, el trastorno y la enfermedad de la criatura que, inevitablemente, se presentarán y torturarán a la madre quien, también inevitablemente, podrá siempre encontrar en sí misma algún indicio de no haber sido todo lo "buena" que debió haber sido (Palomar, 2007, p. 93).

En estos procesos se establecen coordenadas y se marcan límites. Se proporcionan márgenes de interpretación que de antemano excluyen opciones para las personas registradas socialmente en determinada categoría. Los roles socialmente aceptados para mujeres y madres de familia estructuran sus ambiciones y la percepción de los obstáculos que limitan sus posibilidades de salir adelante.

Los cálculos no siempre son explícitos, y con frecuencia son contradictorios. Sin embargo, en la consecución y manejo de finanzas las mujeres incluyen consideraciones con respecto a las posibles fuentes de ingreso - sus capacidades, sus derechos de obtener ayuda o recibir un determinado pago por sus servicios - al destino del ingreso monetario - cuándo y por qué acudir a un médico particular, qué artículos adquirir, qué gastos priorizar -. Entra en juego el miedo, la estimación de riesgos, la percepción de ventaja y desventaja, además de la identidad propia o atribuida. Y es que las transacciones financieras necesariamente involucran formas de predicción y evaluación configuradas dentro de circuitos de significados en los cuales las 
dimensiones sociales, éticas y culturales no se pueden dejar de lado. Aún los regalos y préstamos de amigos y vecinos implican manejarse en procesos de categorización y re-identificación, al igual que los programas gubernamentales y no-gubernamentales.

Como dijimos, no se trata necesariamente de procesos racionales de cálculo, sino de marcos en los que ciertos procesos se habilitan o deshabilitan, de los márgenes para realizar interpretaciones y las herramientas con las que se cuenta para ello. Nos referimos a los marcos de calculabilidad.

Las coordenadas establecidas dentro de estos marcos guían arreglos que involucran relaciones, responsabilidades, complicidades y dependencias y mediante los cuales se forjan las prácticas financieras. La diferenciación identitaria adquiere prominencia en estos marcos, incluyendo consideraciones de género, etnicidad, generación y clase social. Ello implica que el precio por el dinero es elevado en la vida cotidiana de estas mujeres, cuyos escenarios de vida proyectan sus promesas de pago como poco confiables y de "alto riesgo". Los servicios financieros excesivamente caros se explican en parte por "la mermada confiabilidad" de esta población, la asociación de pobreza con ignorancia, la convicción de que carecen de "cultura financiera" y la dificultad de realizar diagnósticos precisos en estos barrios, particularmente dada su reputación como "inseguros" y "rijosos".

Los habitantes de Pueblo Quieto, por ejemplo, se quejan de la discriminación de la que son objeto al vivir en un sitio tachado de hospedar a drogadictos y delincuentes. Silvia nos dice:

Pues mira, aquí está como dicen vulgarmente quemado, porque aquí la verdad había mucho ratero, te soy sincera, pero pues ya a casi todos los agarraron y ya está muy tranquilo aquí, pero pues sí a veces dices vengo de Pueblo Quieto, "uy no, ahí son bien rateros". Luego, luego te dicen, a veces por unos perdemos todos (Silvia: Pueblo Quieto).

Y aunque sí pudimos comprobar que algunos hombres e incluso ciertas mujeres que viven en este asentamiento efectivamente son adictos y hay quienes se dedican al crimen, esto termina afectando a la totalidad de sus habitantes, lo que repercute de diversas maneras y en distintos ámbitos, llevándolos a vivir la discriminación en la calle, el trabajo, la escuela o la iglesia. Cecilia comenta: "Sí, porque uno va caminando y luego, luego la gente piensa como si vamos a salir nomás a robar algo".

Pero, como explica Bauman (2003, p. 120), el "vincular la pobreza con la criminalidad tiene otro efecto: ayuda a desterrar a los pobres del mundo de las obligaciones morales". Afirma que: 
La esencia de toda moral es el impulso a sentirse responsable por el bienestar de los débiles, infortunados y sufrientes; la pobreza convertida en delito tiende a anular ese impulso y es el mejor argumento en su contra. Al convertirse en criminales -reales o posibles -, los pobres dejan de ser un problema ético y nos liberan de aquella responsabilidad. Ya no hay obligación de defenderlos contra la crueldad de su destino; nos encontramos, en cambio, ante el imperativo de defender el derecho y la vida de las personas decentes contra los ataques que se están tramando en callejones, guetos y zonas marginales (Bauman, 2003, p. 120).

Dichos marcos delimitan las opciones posibles para la forja de cálculos económicos y financieros, desde la estimación del salario al que se es merecedor, hasta el destino de los ingresos, pasando por justificaciones de desigualdades en la distribución. También contribuye a estructurar factores de accesibilidad y vulnerabilidad, incidiendo directamente en posibilidades de explotación.

Y en la delimitación de coordenadas para la acción se toman en cuenta también cuestiones emocionales tales como vergüenza, miedo y resistencia a "mostrar necesidad" en conjunción con el acceso a información, la existencia de vínculos de confianza y nociones de seguridad. La humillación de pedir fiado y el no "querer andar en boca de la gente" influyen en la configuración de sus prácticas financieras. Esto puede incrementar los costos de sus transacciones, en tanto que restringe sus opciones y sus horizontes.

En este contexto, se explica que las mujeres no necesariamente se identifiquen como pobres. El pobre es el otro, el desvalido, el que no tiene futuro. Es claro que la etiqueta de "pobre" también es violenta. La noción de "mujer víctima", carente de los medios para procurar un futuro digno a su persona y a su familia, contribuye a su exclusión. El concepto de carencia se teje discursivamente en los marcos de calculabilidad que funcionan a manera de topes en el manejo de sus finanzas.

Así, las relaciones sociales, basadas en diferenciación socio históricamente definida, forman parte intrínseca de las prácticas financieras. Y es que "salir adelante" no es sólo cuestión de tener un techo, poner comida sobre la mesa u obtener un ingreso monetario. También involucra la circulación de información, el manejo de relaciones y habilidades, además de membrecía social y autoafirmación. Cumplir con compromisos, asegurarse protección, adquirir estatus y organizar sus tiempos es tan importante como la alimentación y el resguardo físico. Es por ello que la vergüenza, como lo señalan muchas entrevistadas, es seriamente tomada en cuenta en la valoración de los mecanismos por los cuales pueden optar en sus transacciones económicas. "Mejor hambre", dice una de las entrevistadas, que "humillación". 
Ante este panorama de claroscuros y contradicciones, es evidente que la economía no se puede reducir a una cuestión de pesos y centavos. No se pueden dejar de lado los agentes que inciden en la reproducción de vulnerabilidad, incluyendo los topes que social y culturalmente se imponen al desempeño de las mujeres, las limitaciones de acceso a fuentes de empleo razonables y a servicios financieros apropiados. Y es que las diversas formas de violencia de las que son objeto muchas mujeres en sus esfuerzos por salir adelante no sólo tienen que ver con la avaricia de empresarios, intermediarios y comerciantes sino que encuentran complicidad y legítimo cobijo en marcos de calculabilidad socialmente forjados.

\section{Referencias}

BAUMAN, Zygmunt. Trabajo, consumismo y nuevos pobres. (1. ed. en inglés 1998). Barcelona: Gedisa, 2003.

BENERÍA, Lourdes; ROLDAN, Martha. The crossroads of class and gender: industrial homework, subcontracting, and household dynamics in Mexico city. Chicago: University of Chicago Press, 1987.

CALLON, Michel. (Ed.). The laws of the markets. Oxford: Blackwell Publishers, 1998.

DOUGLAS, Mary; ISHERWOOD, Baron. El Mundo de los Bienes. Hacia una Antropología del consumo. (1. ed. en inglés 1979). México: Grijalvo, 1990.

GONZÁLEZ DE LA ROCHA, Mercedes. Los recursos de la pobreza: familias de bajos ingresos en Guadalajara. Guadalajara: CIESAS, El Colegio de Jalisco y Secretaría de Programación y Presupuesto, 1986.

KNIGHT, Frank H. The Ethics of Competition. The Quarterly Journal of Economics, n. 37, p. 579-624, 1923.

PALOMAR VEREA, Cristina. Maternidad en prisión. Guadalajara: Universidad de Guadalajara, 2007.

SEN, Amartya. Gender and cooperative conflicts. In: TINKER I. (Ed.). Persistent inequalities: women and world development. New York: Oxford University Press, 1990.

VILLARREAL, Magdalena. La economía desde una perspectiva de género: de omisiones, inexactitudes y preguntas sin responder en el análisis de la pobreza. Revista de Estudios de Género La Ventana. Universidad de Guadalajara, Universidad de Guadalajara, n. 25, v. II, p. 7-43, Mayo del 2007.

VILLARREAL, Magdalena. Mujeres, finanzas sociales y violencia económica en zonas marginadas de Guadalajara. CIESAS, IMMG, IJM, PAIMEF, 2009.

ZANOTELLI, Francesco. La circulación de la deuda: códigos culturales y usura rural en Jalisco. In: VILLARREAL, M. (Coord.). Antropología de la deuda: crédito, ahorro, fiado y prestado en las finanzas cotidianas. Ciudad de México: CIESAS, Porrúa y La Cámara de Diputados, 2004. p. 77-112. 